\title{
Antibakteriyel Özelliğe Sahip Aminoglioksimlerin Sentezi ve Özelliklerinin İncelenmesi
}

\author{
Önder ALICI ${ }^{* 1}$, Şule KÖKTEN ${ }^{1}$, İbrahim KARATAŞ ${ }^{1}$, Erdoğan GÜNEŞ ${ }^{2}$ \\ ${ }^{1}$ Selçuk Üniversitesi Fen Fakültesi Kimya Bölümü-Konya \\ ${ }^{2}$ Selçuk Üniversitesi Fen Fakültesi Biyoloji Bölümü-Konya
}

*Sorumlu yazar e-posta: oalici@selcuk.edu.tr katrechemistry@hotmail.com

ikaratas@selcuk.edu.tr erdogangunes@selcuk.edu.tr

Öz

Anahtar kelimeler 4-

Fenoksifenilkloroglioksim; Sübstitüe-aminoglioksim; Anti-bakteriyel özellik;

Organik Sentez
$\mathrm{Bu}$ çalışmada önce difenileterin kloroasetilklorür ile $\mathrm{AlCl}_{3}$ katalizörlüğündeki reaksiyonundan 4kloroasetildifenileter sentezlenmiştir. Sonra bunun nitrosolama metoduyla isonitroso-4asetildifenileteri ve hidroksilaminhidroklorür ile asidik ortamdaki reaksiyonundan 4fenoksifenilkloroglioksimi elde edildi. Daha sonra bu anti-fenoksifenilkloroglioksimin 2-amino-4feniltiyazol ve 2 -fluorenamin ile reaksiyonundan orijinal olarak sübstitüe-aminogliksim türevleri sentezlendi. Elde edilen bileşiklerin yapıları FT-IR ve ${ }^{1} \mathrm{H}-\mathrm{NMR}$ teknikleri kullanılarak aydınlatıldı. Ayrıca sentezlenen iki başlangıç maddesi, sentezlenen sübstitüe-aminoglioksim türevleri ve iki amin bileşiğinin, Escherichia coli ATCC 25922, Pseudomonas aeruginosa ATCC 15442, metisilin duyarlı Staphylococcus aureus ATCC 25923 (MSSA), Klebsiella pneumoniae ATCC 70603, Salmonella enteritidis ATCC 13076 ve Sarcina lutea ATCC 9341 suşlarına karşı anti-bakteriyel özellikleri araştırıldı.

\section{Synthesis of Aminoglioximes with Antibacterial Properties and Investigation of Properties}

\section{Keywords}

4-

Phenoxyphenylchloroglyoxime; Substituted-amino glyoxime; Anti-bacterial property; Organic Synthesis

\begin{abstract}
In this study, firstly 4-chloroacetyldiphenylether was synthesized from the reaction of diphenylether with chloroacetylchloride at $\mathrm{AlCl}_{3}$ catalysis. Then, 4-phenoxyphenylchloroglyoxime was obtained from reaction of isonitroso-4-acetyldiphenylether and hydroxylamine hydrochloride. Subsequently, substituted-amino glyoxime derivatives were originally synthesized from the reaction of this phenoxyphenylchloroglyoxime with 2-amino-4-phenylthiazole and 2-fluorenamine. The structures of the obtained compounds were tried to be elucidated using FT-IR and ${ }^{1} \mathrm{H}-\mathrm{NMR}$ techniques. In addition, Anti-bacterial properties of two starting materials synthesized, substitutedaminoglioxime derivatives synthesized and two amine compounds were investigated against the strains of Escherichia coli ATCC 25922, Pseudomonas aeruginosa ATCC 15442, methicillin sensitive Staphylococcus aureus ATCC 25923 (MSSA), Klebsiella pneumoniae ATCC 70603, Salmonella enteritidis ATCC 13076 and Sarcina lutea ATCC 9341.
\end{abstract}




\section{Giriş}

Oksimler, basitçe aldehit veya ketonların hidroksilamin ile reaksiyonları sonunda oluşan ve yapısında karbon-azot çifte bağı bulunan bileşiklerdir. Oksim ismi, oksi-imin ( $\mathrm{C}=\mathrm{NOH})$ grubunun kısaltmasıdır ve eğer aldehitten elde edilmişlerse aldoksim, ketondan elde edilmişlerse ketoksim olarak isimlendirilirler. Örneğin asetaldehit kullanılarak, asetaldoksim ve aseton kullanılarak asetonoksim Yine bu maddeler "hidroksimino" eki kullanılarak da adlandırılabilirler. Örneğin aseton oksim bileşiği $\left[\mathrm{CH}_{3}-\mathrm{C}(\mathrm{N}-\mathrm{OH})-\mathrm{CH}_{3}\right]$, 2hidroksimino propanon olarak da isimlendirilmektedir. Yine oksimler, nitrozo bileşiklerinin yapı izomeri olduğu için bunların isimlendirilmesinde izonitroso terimi de kullanılabilir. Örneğin $\left(\mathrm{C}_{6} \mathrm{H}_{5}-\mathrm{CO}-\mathrm{CH}=\mathrm{N}-\mathrm{OH}\right)$ bileşiği, Ihidroksiimino asetofenon olarak isimlendirildiği gibi isonitroso asetofenon olarak da isimlendirilmektedir (Smith 1966, Gök 1981).

Oksimlerin bir önemli sınıfı da dioksim yapılardır. Dioksim yapılarda bitişik karbonlarda iki oksim grubu bulundururlar. Bunlar $\alpha-; 1,2-;$ vic-; ve glioksimler şeklinde isimlendirilirler.<smiles>C/C(=N/O)ON</smiles>

Metilglioksim<smiles>C/C(=N\O)C(=NO)c1ccccc1</smiles>

Fenilmetilglioksim
Şekil 1. Glioksimlerin yapısı ve isimleri

Oksimlerin - $\mathrm{OH}$ grubundaki H'nin yerine R- veya R$\mathrm{CO}$ - grubunun geçmesiyle oksimlerin $O$-alkil veya $O$ açil izomerleri oluşmaktadır. Bu yapılara $\left(\mathrm{C}_{6} \mathrm{H}_{5}\right)_{2} \mathrm{C}=\mathrm{N}$ O- $\mathrm{CH}_{2} \mathrm{CH}_{3}$, O-etilasetofenonoksim ve $\mathrm{C}_{6} \mathrm{H}_{5}-\mathrm{CH}=\mathrm{N}-\mathrm{O}$ $\mathrm{COCH}_{3}, \mathrm{O}$-asetilbenzaldoksim örnek olarak verilebilir. Yine oksimlerin -O-R türevlerindeki, alkil grubunun $\mathrm{O}$ üzerinden, $\mathrm{N}$ üzerine geçmesiyle de bir başka oksim türevi olan nitronlar oluşmaktadır. Oksimlerin bu nitron izomerlerine örnek olarak benzofenon- $N$-metil oksim $\left(\alpha, \alpha^{\prime}\right.$-difenil- $N$-metil nitron) verilebilir $\left[\left(\mathrm{C}_{6} \mathrm{H}_{5}\right)_{2} \mathrm{~N}^{+}\left(\mathrm{CH}_{3}\right)-\mathrm{O}^{-}\right]$(Smith 1966, Gök 1981).
Oksimler, yapılarındaki $=\mathrm{N}-\mathrm{OH}$ grubunun hareketli protonundan dolayı hem zayıf asidik, hemde azot atomu üzerindeki ortaklaşmamış elektron çiftinden dolayı zayıf bazik özellik gösterirler. Yani oksimler amfoter özelliğe sahiptirler. Basit oksimlerin pKa'ları 10-12 arasında, 1,2-dioksimlerin pKa'ları ise 7-10 arasında değişiklik göstermektedir (Chakravorty 1974, Kurtoğlu ve Serin 2006).

Oksimler, yapılarında $(\mathrm{C}=\mathrm{N})$ çift bağından dolayı alkenlerdeki cis-trans izomerine benzer olarak, synanti izomeri görülür (Burakevich et al. 1971). Günümüzde ise oksimlerin bu syn-anti izomer isimlendirmeleri Cahn-Ingold-Prelog sistemine göre E/Z olarak belirtilir (Patai 1970, Purtaş 2006).<smiles>O/N=C/c1ccccc1</smiles>

Z-Benzaldoksim

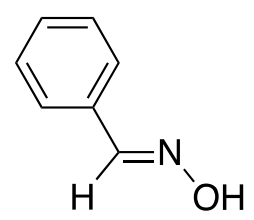

\section{E-Benzaldoksim}

Şekil 2. Aldoksimlerin izomer yapıları

Oksimler, kimyanın birçok alanında değişik amaçlarla kullanılmaktadır. Özellikle dioksimler, geçiş metalleri ile kolay kompleks oluştururlar ve bu metal iyonlarının spektrofotometrik tayininde türevlendirici madde olarak sıklıkla kullanılırlar (Sing et al. 1979, Akiba and Freisher 1982, Keeney and Asare 1984). Ayrıca bazı oksim ve türevleri fotoğraf, boya, kauçuk endüstrisi, motor yağlarının, boyaların, epoksit reçinelerin, lastiklerin vb. bazı özelliklerinin iyileştirilmesi için katkı maddesi olarak kullanıldıkları bilinmektedir (Kara 1995). Yine birçok oksim ve onların alkil ve amino türevleri fizyolojik ve biyolojik aktif özelliklere sahip oldukları bilinmektedir (Leclerc et al. 1977, Leclerc et al. 1980, Massolini et al. 1989).

Oksim ve oksim eterler, yapılarında taşıdıkları gruplardan dolayı geniş bir farmakolojik aktivite sahiptirler ve tedaviye girmiş pekçok ilaç örneği vardır. Örneğin, arilfuril ketoksim ve eterleri ile fenil piridil ketoksiminler de antifungal-antibakteriyel aktivite gösteren bileşikler olarak literatüre geçmiştir (Massolini et al. 1989, Massolini et al. 
1996). Yine Bozdağ vd. (1998) tarafından hazırladıkları asetofenon, haloperidol ve primaperon oksim eterleri antidepresan etki gösterdiği bildirilmiştir. Bazı siklik ariliden ketoksimlerin sitotoksik etkileri, 55 insan tümörüne karşı değerlendirilmiş, birçok neoplastik hastalıkta, özellikle de lösemide selektif toksisite gösterdiği bulunmuştur (Dimmock et al. 1994).

Bu çalışmada önce, difenileterin gerekli reaktifler kullanılarak, biz dizi reaksiyonları sonucu 4fenoksifenilkloroglioksimi sentezlendi. Sonra bunun 2-amino-4-feniltiyazol ve 2-fluorenamin ile reaksiyonundan, yeni sübstitüe-aminoglioksim türevleri sentezlendi. Bileşiklerin yapıları hem literatür bilgileri ile hem de FT-IR ve ${ }^{1} \mathrm{H}-\mathrm{NMR}$ teknikleri kullanılarak aydınlatılmaya çalışıldı.

Sentezlenen sübstitüe-aminoglioksim türevlerinin anti-bakteriyel özellikleri, Escherichia coli ATCC 25922, Pseudomonas aeruginosa ATCC 15442, metisilin duyarlı Staphylococcus aureus ATCC 25923 (MSSA), Klebsiella pneumoniae ATCC 70603, Salmonella enteritidis ATCC 13076 ve Sarcina lutea ATCC 9341 standart suşlarına karşı araştırıldı.

\section{Materyal ve Metot}

\subsection{4-Kloroasetildifenileter Sentezi (I)}

$\mathrm{Bu}$ maddenin sentezi literatürde belirtildiği gibi gerçekleştirildi(Cavallini et al. 1963, Coşkun ve Yılmaz 2008).

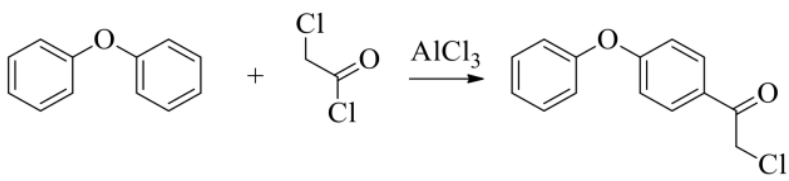

Şekil 3. 4-Kloroasetildifenileter'in Sentez Şeması

Bir soğutucu sistemi $\left(-10^{\circ} \mathrm{C}\right)$ üzerine yerleştirilen $250 \mathrm{~mL}$ 'lik balona, $40 \mathrm{~mL}$ diklormetan, $0.1 \mathrm{~mol} \mathrm{AlCl}_{3}$ ve $0.1 \mathrm{~mol}$ asetilklorür ilave edildi. Bu karışım üzerine, $40 \mathrm{~mL}$ diklorometanda çözülmüş $0.1 \mathrm{~mol}$ difenileter yavaş yavaş damlatıldı. Yaklaşık 2 saat sonra oluşan koyu renkli karışım bir gece oda sıcaklığında bekletildi. Sonra karışım $300 \mathrm{~g}$ buz ve 5 $\mathrm{ml}$ der. $\mathrm{HCl}$ üzerine karıştırılarak ilave edildi ve $\mathrm{pH}$ : 5-6 oluncaya kadar su ile yıkandı. Elde edilen açık sarı katı madde, eter-hekzan (1/2) karışımından kristallendirildi.

E.n: $54-56^{\circ} \mathrm{C}$ [lit. $56-57^{\circ} \mathrm{C}$ ]; Verim: $\% 62$

\subsection{4-Fenoksifenilhidroksimoil klorür Sentezi (II)}

4-Fenoksifeniloksihidraksimoil klorür veya [Nhidroksil-2-okso-2-(4-feniloksofenil) asetimido klorür] olarak isimlendirilen bu bileşik, literatür bilgilerinden uyarlanarak sentezlendi (Mohammed and Nagendrappa 2003, Coşkun ve Yılmaz 2008).

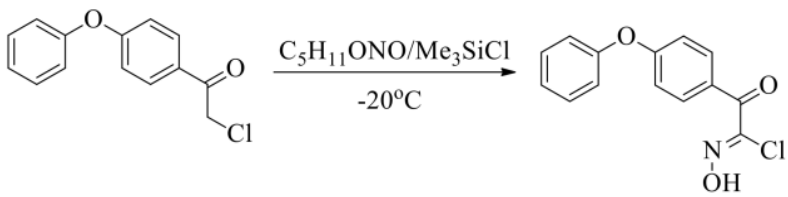

Şekil 4. 4-Fenoksifenilhidroksimoil klorür'in Sentez Reaksiyonu

$100 \mathrm{~mL}$ 'lik üç boyunlu bir balona, $20 \mathrm{~mL}$ diklorometanda çözülmüş $10 \mathrm{mmol}$ 4-kloro asetildifenileter $-20{ }^{\circ} \mathrm{C}$ ye kadar soğutularak üzerine $5 \mathrm{~mL}$ diklorometanda çözülmüş $11 \mathrm{mmol} \mathrm{Me}_{3} \mathrm{SiCl}$ ilave edildi. Bu çözelti içerisinden 30 dakika süreyle kuru $\mathrm{HCl}$ gazı geçirildi. Sonra $11 \mathrm{mmol}$ izopentilnitrit ilave edilerek bir süre karıştırıldı. Daha sonra karışım 1 gün bekletildi ve yeterince hegzan ilave edilerek çökmesi sağlandı. Oluşan kristaller eter-hekzan (1/2) karışımından tekrar kristallendirildi.

E.n: $125-127^{\circ} \mathrm{C} \quad$ [lit. $128^{\circ} \mathrm{C}$ ]; Verim: $\% 74$

\subsection{4-Fenoksifenilkloroglioksin Sentezi (III)}

4-Fenoksifenilkloroglioksim veya [N-hidroksil-2(hidroksiimino)-2-(4-fenilokso fenil)-asetimido klorür] olarak isimlendirilen bu madde, literatür bilgilerine göre sentezlenmiştir (Karipcin et al., 2006; Yılmaz, 2007).

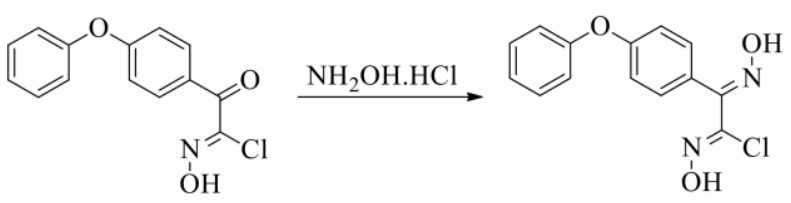

Şekil 5. 4-Fenoksifenilkloroglioksim'in Sentez Reaksiyonu

$100 \mathrm{~mL}$ 'lik bir balonda $10 \mathrm{mmol}$ fenoksifeniloksihidraksimoil klorür $25 \mathrm{~mL}$ alkolde çözüldü ve $15 \mathrm{mmol} \mathrm{NH}_{2} \mathrm{OH}$.HCl'nin sudaki çözeltisi karıştırılarak ilave edilerek, yaklaşık 6 saat geri soğutucu altında $40{ }^{\circ} \mathrm{C}^{\prime}$ de karıştırıldı. Sonra karışım 4 gün kendi halinde bekletildi, çöken madde süzüldü, su ile yıkandı ve etanolden tekrar kristallendirildi. 
E.n: $180-182^{\circ} \mathrm{C}$ [lit. $\left.188^{\circ} \mathrm{C}\right]$; Verim: $\% 72$

\subsection{4-Feniltiyazol-2-aminofenoksifenilglioksim Sentezi (IV)}

Bu madde [N'-hidroksi-2-(hidroksimino)-2-(4fenoksifenil)-N-(4-fenil tiyazol-2-yl)asetimitamit], literatür bilgilerinden faydalanılarak orijinal olarak sentezlenmiştir (Taş et al. 2004, Özdamar 2015).

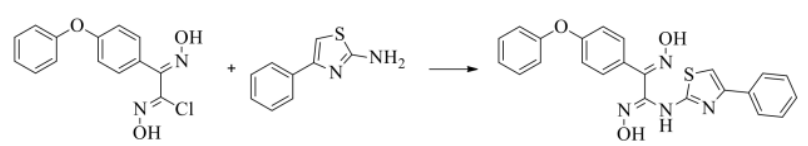

Şekil 6. 4-Feniltiyazol-2-aminofenoksifenilglioksim'in Sentez Reaksiyonu

$100 \mathrm{~mL}$ 'lik bir balonda, $10 \mathrm{mmol}$ fenoksifenilkloroglioksimin $30 \mathrm{~mL}$ etilalkol'deki çözeltisi $0^{\circ} \mathrm{C}^{\prime}$ ye soğutuldu ve üzerine $20 \mathrm{~mL} 1 \mathrm{~N}$ $\mathrm{Na}_{2} \mathrm{CO}_{3}$ çözeltisi ilave edildi. Daha sonra, $12 \mathrm{mmol} 2-$ amino-4-feniltiyazol'ün $20 \mathrm{~mL}$ diklormetandaki çözeltisi ilave edildi ve oluşan karışım önce $0^{\circ} \mathrm{C}$ 'de, sonra oda sıcaklığında 2 saat karıştırıldı. Reaksiyon karışımı bir gece buzdolabında bekletildi. Oluşan sarımsı çökelek süzüldü, önce eter, sonra su ile yıkandı ve etanol-su karışımından (1/4) tekrar kristallendirilerek, vakumlu etüvde $60 \quad{ }^{\circ} \mathrm{C}^{\prime} \mathrm{de}$ kurutuldu.

\section{E.n: $167^{\circ} \mathrm{C}$; Verim: \% 68}

\subsection{2-fluorenaminofenoksi fenilglioksim Sentezi} (V)

Bu madde [N-(9H-fuloren-2-yl)- $\mathrm{N}^{\prime}$-hidroksi-2(hidroksiimino)-2-(4-fenil oksofenil) asetimidamit], benzer literatür bilgilerinden uyarlanarak orijinal olarak sentezlenmiştir (Taş et al. 2004, Özdamar et al. 2015).

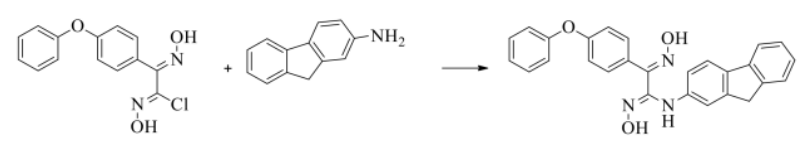

Şekil 7. 2-fluorenaminofenoksi fenilglioksim'in Sentez Reaksiyonu

Soğutucu düzeneğine yerleştirilmiş 100 mL' lik bir balonda, $11 \mathrm{mmol}$ 2-fluorenamin'in $20 \mathrm{~mL}$ THF'daki çözeltisi konularak $-15{ }^{\circ} C^{\prime}$ ye kadar soğutuldu, üzerine $1,50 \mathrm{~mL}$ trietilaminin $10 \mathrm{~mL}$ THF'daki çözeltisi ilave edildi. Sonra karışıma, $10 \mathrm{mmol} 4-$ fenoksifenilkloroglioksim'in 30 mL THF'daki çözeltisi damla damla ilave edildi ve karışım aynı sıcaklıkta 5 saat karıştırıldı. Reaksiyon ortamında çöken madde (tuz) süzüldükten sonra, elde edilen organik fazın çözücüsü evaparatörde uzaklaştırılarak yağımsı bir tabaka elde edildi. Bunun üzerine diklormetan ilave edilerek çözünmesi sağlandı ve üzerine yeterince $n$ hekzan ilave edilerek madde çöktürüldü. Çöken madde süzüldü, $n$-hekzan ve eter ile yıkandı ve izopropil alkolden tekrar kristallendirildi.

E.n: $175-178{ }^{\circ} \mathrm{C}$; Verim: $\% 70$

\subsection{Sübstitüe-aminofenoksifenilglioksimlerin Antibakteriyel Aktiviteleri}

Bu çalışmada sentezlenen, fenoksifeniloksihidraksimoil klorür (II), 4-fenoksi fenilkloroglioksim (III), 4-Feniltiyazol-2aminofenoksifenilglioksim [N'-hidroksi-2(hidroksimino)-2-(4-fenoksifenil)-N-(4-feniltiyazol-2yl)asetimitamit $\quad$ (IV), 2-fluorenamino fenoksifenilglioksim [N-(9H-fuloren-2-yl)- $N^{\prime}$ hidroksi-2-(hidroksiimino)-2-(4-fenil okso fenil)asetimidamit] (V) ve sentezlerde kullanılan 2amino-4-feniltiyazol (VI) ile 2-amino fluoren (VII) bileşiklerinin antibakteriyel aktiviteleri yönünden incelemeleri yapılmıştır. Bunun için Escherichia coli ATCC 25922, Pseudomonas aeruginosa ATCC 15442, metisilin duyarlı Staphylococcus aureus ATCC 25923 (MSSA), Klebsiella pneumoniae ATCC 70603, Salmonella enteritidis ATCC 13076 ve Sarcina lutea ATCC 9341 standart suşları kullanıldı. Bu testlerde kullanılan standart suşlar, Selçuk Üniversitesi Fen Fakültesi Biyoloji Bölümü Mikrobiyoloji Araştırma Laboratuvarı'ndan temin edildi ve çalışma aynı laboratuvarda gerçekleştirildi. Sentezlenen bileşiklerin antibakteriyel aktivitesini belirlemek amacıyla sıvı mikrodilüsyon yöntemi kullanıldı. Testlerde kullanılan standart mikroorganizmalar, Brain-Hearth Infusion Broth besiyerine ekilerek, 37 ${ }^{\circ} C^{\prime}$ de bir gece inkübasyona bırakıldı. Testlerde steril $\mathrm{U}$ tabanlı mikropleytlerin her kuyucuğuna $100 \mu \mathrm{l}$ Mueller-Hinton Broth besiyeri ilave edildi. Bir gecelik inkübasyondan sonra BHIB besiyerinde üreyen suşlar, steril serum fizyolojik içerisinde bulanıklık dereceleri $0.5 \mathrm{Mc}$ Farland $\left(10^{8}\right.$ koloni oluşturan birim $/ \mathrm{ml}$ ) olacak şekilde ayarlandı. Kuyucuklardaki inokulumun son konsantrasyonu 
$5 \times 10^{5} \mathrm{kob} / \mathrm{ml}$ ve kimyasal maddelerin konsantrasyonu ise (II) $7.25-0.00354 \mathrm{mg} / \mathrm{ml}$, (III) $8.0-0.00390 \mathrm{mg} / \mathrm{ml}$, (IV) $10.0-0.00488 \mathrm{mg} / \mathrm{ml}$, (V) $6.5-0.00317 \mathrm{mg} / \mathrm{ml}$, (VI) $6.0-0.00293 \mathrm{mg} / \mathrm{ml}$ ve (VII) $6.25-0.00305 \mathrm{mg} / \mathrm{ml}$ olarak uygulandı. Pozitif kontrol olarak Gentamisin antibiyotiği kullanıldı. Pleytler $37{ }^{\circ} \mathrm{C}^{\prime}$ de ve 24 saat inkübe edildi. İnkübasyondan sonra her kuyucuğa $20 \mu \mathrm{l} 2,3,5-$ trifenil tetrazolyumklorit $(\% 0,5)$ solüsyonu eklenerek, $37{ }^{\circ} \mathrm{C}^{\prime}$ de $30 \mathrm{dk}$ tekrar inkübasyona bırakıldı. Bu inkübasyon sonunda gözle görülebilir bir üremenin olmadığı, yani pembe-kırmızı renk vermeyen son kuyucuk Mik (Minimum İnhibisyon Konsantrasyonu) olarak değerlendirildi (Arda 2000, Zengin et al. 2014).

Çizelge 1. Test bileşiklerin standard mikroorganizmalara karşı belirlenen Minimum İnhibisyon Konsantrasyonu (MiK) değerleri

\begin{tabular}{|c|c|c|c|c|c|c|c|}
\hline & \multicolumn{6}{|c|}{$\begin{array}{l}\text { Maddelerin Mik Değerleri } \\
\qquad(\mathrm{mg} / \mathrm{ml})\end{array}$} & $\begin{array}{c}\text { Gentamici } \\
\text { n'in Mik } \\
\text { Değeri } \\
(\mu \mathrm{g} / \mathrm{ml})\end{array}$ \\
\hline $\begin{array}{l}\text { Mikroorganiz } \\
\text { maları }\end{array}$ & II & III & IV & $\mathbf{v}$ & VI & VII & \\
\hline $\begin{array}{l}\text { Escherichia coli } \\
\text { ATCC } 25922\end{array}$ & - & - & - & - & - & - & 2.44 \\
\hline $\begin{array}{l}\text { Pseudomonas } \\
\text { aeruginosa } \\
\text { ATCC }\end{array}$ & 1.81 & $\begin{array}{l}2 . \\
0\end{array}$ & $\begin{array}{c}1.1 \\
5\end{array}$ & 2.5 & $\begin{array}{c}1.5 \\
6\end{array}$ & - & 9.76 \\
\hline $\begin{array}{l}\text { Staphylococcus } \\
\text { aureus ATCC } \\
25923\end{array}$ & $\begin{array}{c}0.01 \\
4\end{array}$ & $\begin{array}{l}0 . \\
5\end{array}$ & $\begin{array}{c}0.4 \\
3\end{array}$ & 0.02 & - & $\begin{array}{c}1.6 \\
2\end{array}$ & 2.44 \\
\hline $\begin{array}{l}\text { Klebsiella } \\
\text { pneumoniae } \\
\text { ATCC }\end{array}$ & 1.81 & $\begin{array}{l}1 . \\
0\end{array}$ & $\begin{array}{c}1.7 \\
4\end{array}$ & 2.5 & - & $\begin{array}{c}0.8 \\
1\end{array}$ & 2.44 \\
\hline $\begin{array}{l}\text { Salmonella } \\
\text { enteritidis } \\
\text { ATCC } 13076\end{array}$ & 1.81 & - & - & - & - & - & 4.88 \\
\hline $\begin{array}{l}\text { Sarcina lutea } \\
\text { ATCC } 9341\end{array}$ & $\begin{array}{l}0.05 \\
6\end{array}$ & - & - & $\begin{array}{c}0.07 \\
8\end{array}$ & - & - & 4.88 \\
\hline
\end{tabular}

Çizelge-1'de verilen değerlerden, maddelerin 0.014 $4.9 \mathrm{mg} / \mathrm{ml}$ konsantrasyon aralığında değişen oranlarda antimikrobiyal aktivite gösterdikleri belirlendi. Minimum inhibisyon konsantrasyon değerleri, kontrol antibiyotiği ile kıyaslandığında, bazı maddelerin bazı bakterilere karşı güçlü antimikrobiyal etki gösterdiği belirlenmiştir. Elde edilen sonuçlara göre çalışmada kullanılan maddelerin hiçbirinin $E$. coli standart suşuna karşı herhangi bir etki göstermediği tespit edilmiştir. II, ve V no'lu bileşiklerin Gram (+) olan S. aureus ve $S$. lutea standart bakterilerine karşı yüksek antibakteriyel aktivite gösterdiği görülmüştür. II no'lu bileşiğin Gram (-) P.aeruginosa, K. pneumoniae ve $S$. enteritidis bakterilerine karşı $1.81 \mathrm{mg} / \mathrm{ml}$ konsantrasyonda etkili olduğu görülmüştür. $\mathbf{V}$ no'lu bileşiğinin P.aeruginosa ve $K$. pneumoniae bakterilerine karşı $2.5 \mathrm{mg} / \mathrm{ml}$ konsantrasyonda etkili olduğu, fakat $S$. enteritidis bakterisine etki etmediği görülmüştür. IV numaralı bileşiğin ise Gram (+) $S$. aureus standart bakterisine $0.43 \mathrm{mg} / \mathrm{ml}$ konsantrasyonda etkili olduğu görülürken, $P$. aeruginosa bakterisine $1.15 \mathrm{mg} / \mathrm{ml}$ konsantrasyonunda, Gram (-) K. pneumoniae bakterisine $1.74 \mathrm{mg} / \mathrm{ml}$ konsantrasyonda etkili olduğu belirlenmiştir. Satın alınarak sentezlerde doğrudan kullanılan VII numaralı amin bileşiği $S$. aureus ve $K$. pneumoniae bakterilerine karşı 1.62 ve $0.81 \mathrm{mg} / \mathrm{ml}$ konsantrasyonda, VI numaralı amin bileşiğinin ise, sadece $P$. aeruginosa bakterisine 1.56 $\mathrm{mg} / \mathrm{ml}$ konsantrasyonda etki gösterdiği tespit edilmiştir. Çizelge-1'den görüldüğü gibi, yapısında hem oksim grubu hem de klor atomu bulunduran 4fenoksifeniloksihidraksimoil klorür (II) ve 4fenoksifenilkloroglioksim (III) bileşikleri S. aureus bakterisine karşı oldukça etkilidirler. Sentezlerde satın alınarak kullanılan 2-aminobenzotiyazol ve 2 aminofluoren (VI ve VII) bileşikleri bakteriler üzerine yeterince etkili değilken, 4fenoksifenilkloroglioksime bağlanmış hallerinin (IV ve $V$ ) daha etkili olduğu görülmektedir. Sonuç olarak, Çizelge 1'de de görüldüğü gibi, test edilen II ve $V$ no'lu maddelerin Gram (+) bakterilere karşı daha yüksek antibakteriyel aktiviteye sahip oldukları söylenebilir.

\section{Bulgular}

Bu çalışmada, 4-fenoksifenilkloroglioksimi ve bunun bazı aromatik aminler ile reaksiyonundan, yeni sübstitüe-aminoglioksim bileşiklerinin sentezlenmesi ve bu bileşiklerin biyolojik aktivitelerinin incelenmesi hedeflenmiştir.

Bunun için önce, difenileterin kloroasetilklorür ile $\mathrm{AlCl}_{3}$ katalizörlüğündeki reaksiyonundan 4kloroasetildifenileter (I), sonra bunun nitrosolama metoduyla 4-fenoksifeniloksihidraksimoil klorür (II) ve hidroksilaminhidroklorür ile reaksiyonundan 4fenoksifenilkloroglioksim (III) literatür bilgileri veya onların yardımı ile elde edildi (Cavallini et al. 1963, Coşkun ve Yılmaz 2008, Mohammed and 
Nagendrappa 2003, Karipcin et al. 2006, Yılmaz 2007). Daha sonra bu 4-fenoksifenilkloroglioksimin, 2-amino-4-feniltiyazol ve 2-fluorenamin ile reaksiyonundan yine benzer literatür bilgileri ışığında orijinal olarak sübstitüe-aminoglioksim bileşikleri sentezlenmiştir (Taş, 2004; Özdamar, 2015). Orijinal olarak elde edilen bileşiklerin ${ }^{1} \mathrm{H}-\mathrm{NMR}$ değerleri incelendiğinde (Şekil 8 a-b), oksim gruplarına ait O-H pikleri, 13.60-12.60 ppm; $\mathrm{N}-\mathrm{H}$ pikleri, 8.43-8.17 ppm; C-H (arom); 8.01-7.09 ppm; C-H (alif.), 4.35-1.39 ppm değerleri arasında yer almaktadır. Sentezlenen bileşiklerin ${ }^{1} \mathrm{H}-\mathrm{NMR}$ değerleri literatürde verilen benzer bileşikler ile uygunluk göstermektedir (Kleinspehn et al. 1967, Silverstein et al. 1974, Balcı 2004).

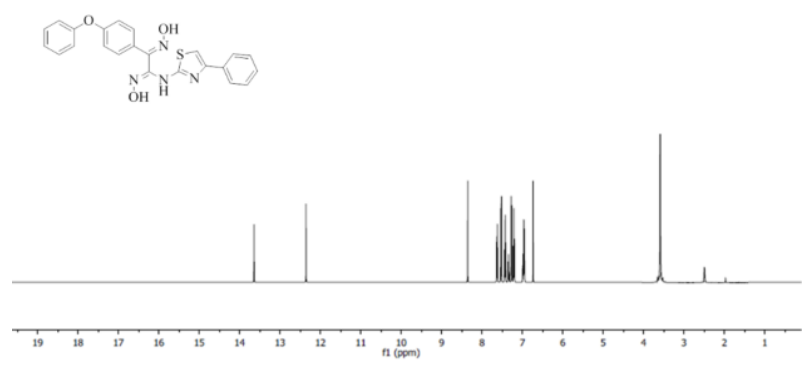

Şekil 8a. 4-Feniltiyazol-2-aminofenoksifenilglioksim'in ${ }^{1} \mathrm{H}$ NMR spektrumu (DMSO- $d_{6}$ )

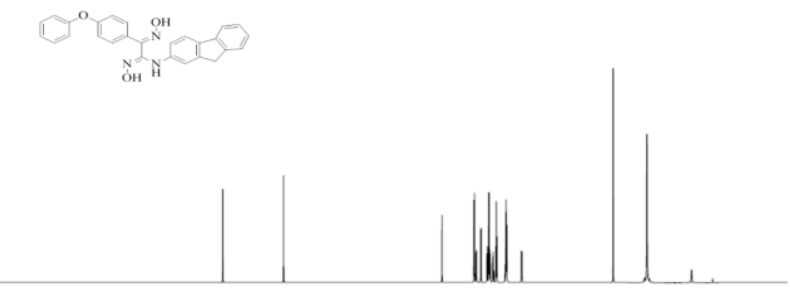

Şekil 8b. 2-Fluorenaminofenoksifenilglioksim'in ${ }^{1} \mathrm{H}-\mathrm{NMR}$ spektrumu (DMSO- $d_{6}$ )

Elde edilen bileşiklerin FT-IR gerilme titreşim değerleri (Şekil 9 a-b); N-H: 3400-3342; O-H: 32603120; C-H (arom): 3050-3010; C=N: 1650-1600; C=C (arom): 1490-1450; C-O (eter): $1150-1050$ ve N-O: 965-900 $\mathrm{cm}^{-1}$ dir. Bu değerler, benzer çalışmalar ile uyum halindedir (Gül ve Bekaroğlu 1983).

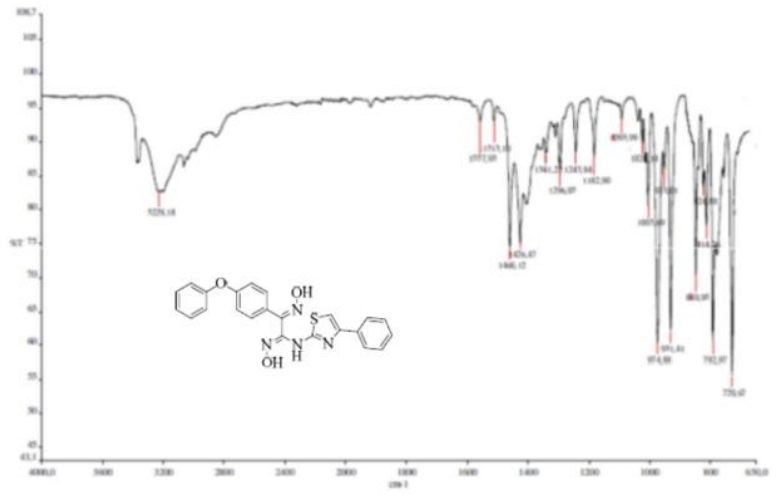

Şekil 9a. 4-Feniltiyazol-2-aminofenoksifenilglioksim'in FT-IR Spektrumu

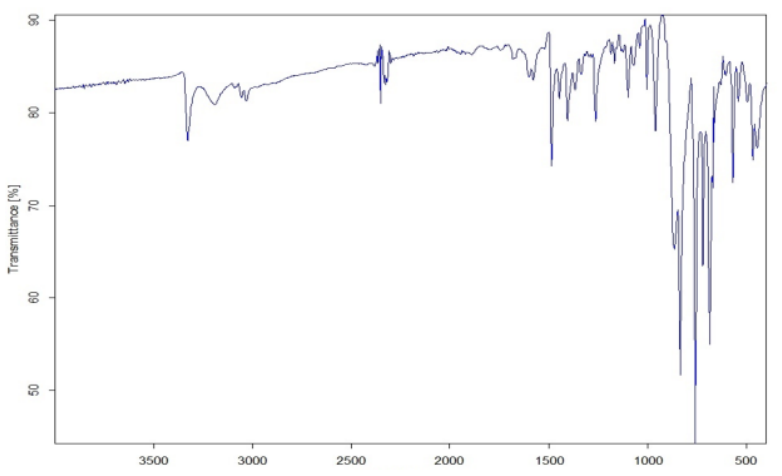

Şekil 9b. 2-Fluorenaminofenoksifenilglioksim bileşiğinin FT-IR Spektrumu

Çalışmada sentezlenen başlangıç maddeleri ile orijinal olarak sentezlenen iki bileşiğin ve satın alınarak sentezlerde kullanılan iki maddenin (II, III, IV, V, VI ve VII) antibakteriyel aktiviteleri, Escherichia coli, Pseudomonas aeruginosa, metisilin duyarlı Staphylococcus aureus, Klebsiella pneumoniae, Salmonella enteritidis ve Sarcina lutea suşlarına karşı yapılmıştır. Özellikle, yapısında hem oksim grubu hem de klor atomu bulunduran 4fenoksifeniloksihidraksimoil klorür (II) ve 4fenoksifenilkloroglioksim (III) bileşiklerinin S. aureus bakterisine karşı oldukça etkili olduğu bulunmuştur. Yine sentezlerde satın alınarak kullanılan 2-amino-4feniltiyazol ve 2-aminofluoren (VI ve VII) bileşiklerinin bakteriler üzerine yeterince etkili değilken, 4-fenoksifenilkloroglioksime bağlanmış hallerinin (IV ve V) daha etkili olduğu görülmektedir. Sonuç olarak, test edilen maddelerden II ve V no'lu bileşiklerin Gram (+) bakterilere karşı daha yüksek anti bakteriyel aktiviteye sahip oldukları söylenebilir. 


\section{Teşekkür}

Bu çalışma, 14201012 nolu Araştırma Projesi olarak Selçuk Üniversitesi Bilimsel Araştırma Projeleri Koordinatörlüğü tarafından mali olarak desteklenmiştir.

\section{Kaynaklar}

Akiba, K. and Freisher, H., 1982. The Role of the Solvent in Equilibrum and Kinetic Aspect of Metal Chelate Extractions. Analytica Chimica Acta, 136, 329-337.

Arda, M., 2000. Temel Mikrobiyoloji. Medisan Yayınevi, No: 46, 2. Baskı, Ankara, 1-80

Balcı, M., 2004. Nükleer Manyetik Spektroskopisi. ODTÜ Yayıncılık, 452, Ankara, 10-50.

Bozdağ, O, Gümüşel B, Demirdamar R, Büyükbingöl $E$, Rolland, Y, Ertan R., 1998. Synthesis of some novel oxime ether derivatives and their activity in the 'behavioral despair test', European Journal of Medicinal Chemistry, 33, 133-141.

Burakevich, J.V., Lore, A.M., ve Volpp, G.P., 1971. Phenylglyoxime separation, characterization, and structure of three Isomers, The Journal of Organic Chemistry, 36, 1-4.

Cavallini, G., Massarani, E., Nardi, D., Mauri, L., Tenconi, F., Pacchiano, F., and Mantegazza, P., 1963. "Antibacterial Agents. Some New Halomethyl Aryl Ketones" Journal of Medicinal Chemistry, 6(5), 573578.

Chakravorty, A., 1974. Structural chemistry of transition metal complexes of oximes, Coordination Chemistry Reviews, 13 (1), 1-46.

Coşkun, A. and Yılmaz, F., 2008. Synthesis and chracterization of 4(alkylaminoisonitrosoacetyl)diphenyl ether and some of their metal Complexes, Turkish Journal of Chemistry, 32, 305-312.

Dimmock, J.R., Sidhu, K.K., Chen, M., Li, J, Quail, J.W., Allen, T.M, ve Kao, G.Y., 1994. Synthesis and Cytotoxic Evaluation of Some Cyclic Arylidene Ketones and Related Oximes, Oxime Esters, and Analogs, Journal of Pharmaceutical Sciences, 83(6), 852-858.
Gök, Y., 1981. Yeni $\alpha$-Dioksim sentezleri, geometrik izomerleri ve bazı metallerle kompleks formasyonlarının incelenmesi, Doktora Tezi, Karadeniz Teknik Üniversitesi Fen Bilimleri Enstitüsü, Trabzon, 110.

Gül, A., and Bekaroğlu, O., 1983. Syntheses of NN'-bis(4'benzo[15-crown-5])diaminoglyoxime and its complexes with Copper(II), Nickel(II), Cobalt(II), Cobalt(III), Palladium(II), Platinum(II), and UranyI(VI), Journal of The Chemical Society-dalton Transactions, 12, 2537-2541.

Kara, A., 1995. Çeşitli oksimlerin sentezi ve özelliklerinin incelenmesi, Yüksek Lisans Tezi, Uludağ Üniversitesi Fen Bilimleri Enstitüsü, Bursa, 68.

Karipcin, F., Arabalı, F. and Karataş, I., 2006. Synthesis and chracterization of 4-aryl- aminobiphenylglyoximes and their complexes, Journal of the Chilean Chemical Society, 51(3), 982-985.

Keeney, M.E. ve Asare, K.O., 1984. Transition Metal Hydroxyoxime Complexes, Coordination Chemistry Reviews, 59, 141-201.

Kleinspehn, G.G., Jung, J.A. and Studniaez, S.A., 1967. The Chemical Shift of the Hydroxyl Proton of Oxime in Dimethyl Sulfoxide, The Journal of Organic Chemistry, 32(2), 460-462.

Kurtoğlu, M. ve Serin, S., 2006. Oksimler: Sentezi, Reaksiyonları ve Metal Kompleksleri, KSÜ-Fen ve Mühendislik Dergisi, 9(2), 25-32, Kahramanmaraş.

Lecterc, G., Mann, A. and Schwartz, J., 1980. Synthesis and adrenergic bloking activity of new aliphatic oxime ethers, Journal of Medicinal Chemistry, 23(6), 620624.

Lecterc, G., Mann, A., Wermuth, C.G., Bieth, N. and Schwartz, J., 1977. Synthesis and adrenergic bloking activity of a novel class aromatic oxime ethers, Journal of Medicinal Chemistry, 20(12), 1657-1662.

Massolini G, Kitsos M, Gandini C., Caccialanza G, 1989. Fungicidal activity of a series of phenyl pyridy ketoximes and their O-acetyl derivatives, Pesticide Science, 26, 209-214. 
Massolini G, Carmellino ML, Baruffini A, 1996. Fungicidal activity of arylfuryl ketoximes, Farmaco (Societa Chimica Italiana: 1989), 51(4), 287-292.

Mohammed, A.H. ve Nagendrappa, G., 2003. A remarkably simple $\alpha$-oximation of ketones to 1,2 dione monooximes using the chlorotrimethylsilaneisoamyl nitrite combination, Tetrahedron Letters, $\mathbf{4 4}$ (13), 2753-2755.

Özdamar, H.N., Alıcı, Ö. ve Karataş, İ.,2015. New aminoketo oxime derivatives: Synthesis and Characterization, Journal of Selcuk University Natural and Applied Science, 4(4), 1-6, Konya.

Patai, S., 1970. The chemistry of Carbon-Nitrogen double bond, 360, Interscience Publisher, London, 1-100.

Purtaş, F., 2006. Suda çözünebilir yeni vic-dioksim ligandı ve bazı metal Komplekslerinin Sentezi, Yüksek Lisans Tezi, Kahramanmaraş Sütçü İmam Üniversitesi Fen Bilimleri Enstitüsü, Kahramanmaraş, 83.

Silverstein, R.M., Bassler, G.C. ve Morrill, T.C., 1974. Spectrometric identification of organic compounds, John Wiley, 159-229.

Singh, R.B., Garg, B.S. ve Singh, R.P., 1979. Oximes as spectrophotometric reagents-a review. Talanta, 26(6), 425-444.

Smith, P.A.S., 1966. The Chemistry of Open-chain Organic Nitrogen Compounds: Derivatives of oxidized nitrogen: hydrazines to nitrates, V.2, New York, 28-68.

Taş E., Ulusoy M. ve Güler M., 2004. Synthesis, characterization and redox properties of a new vicdioxime and its transition metal complexes, Transition Metal Chemistry, 29, 180-184.

Yılmaz, F., 2007. Fenoksifenilglioksim ve bazı geçiş metal komplekslerinin sentezi, Yüksek Lisans Tezi, Selçuk Üniversitesi Fen Bilimleri Enstitüsü, Konya, 89.

Zengin, G., Uysal, A., Güneş, E., Aktümsek, A., 2014. Survey of phytochemical composition and biological effects of three extracts from a wild plant. A potential source for functional food ingredients and drug formulations. PLOS ONE, 9(11): 1-13. 